My own personal hell: Approaching and exceeding thresholds of too much alcohol

Authors: Mark Burgess ${ }^{1}$, Richard Cooke ${ }^{2}$ \& Emma L Davies ${ }^{1}$

1. Department of Psychology, Oxford Brookes University, Oxford, OX3 0BP, United Kingdom

2. Institute for Psychology, Health \& Society, University of Liverpool, Liverpool, L69 7ZA, United Kingdom

Corresponding author: Emma L Davies edavies@brookes.ac.uk 01865485046

This study was funded by Oxford Brookes University.

The authors declare no conflicts of interest.

Acknowledgements: We would like to thank the reviewers for their constructive comments 


\title{
My own personal hell: Approaching and exceeding thresholds of too much alcohol
}

\begin{abstract}
Objectives: Government guidelines aim to promote sensible alcohol consumption but such advice is disconnected from people's lived experiences. This research investigated how people construct personal thresholds of 'too much' alcohol.

Design and measures: 150 drinkers completed an online survey (Mage=23.29(5.51);

64.7\%female). Participants were asked whether they had an intuitive sense of what constitutes too much alcohol. They wrote open-ended descriptions of how that threshold had been established and how it felt to approach/exceed it. These qualitative accounts were coded using thematic analysis and interpreted with an experiential theoretical framework.
\end{abstract}

Results: Personal thresholds were based on previously experienced embodied states rather than guidelines, or health concerns. Describing the approach to their threshold, $75 \%$ of participants fell into two distinct groups. Group 1's approach was an entirely negative (nausea/anxiety) and Group 2's approach was an entirely positive, embodied experience (relaxed/pleasurable). These groups differed significantly in awareness of alcohol's effects, agency and self-perceptions, but not on alcohol consumption. Exceeding their threshold was an entirely negative embodied experience for all.

Conclusion: These findings illustrate that people are guided by experientially grounded conceptions of consumption. Interventions could target different groups of drinker according to their embodied experience during the approach to 'too much' alcohol.

Keywords: Alcohol limits; Experiential; Consumption; AUDIT; Embodiment; Health guidelines; Heavy drinking 


\section{My own personal hell: Approaching and exceeding thresholds of too much alcohol}

\section{Introduction}

Determining a safe level of alcohol consumption has challenged medical authorities, governments and individual citizens alike. It has largely been a challenge of achieving balance between perceived objective (Ronksley, Brien, Turner, Mukamal, \& Ghali, 2011) and subjective (Peele \& Brodsky, 2000) benefits of alcohol, and the litany of short and long term health risks to which alcohol contributes worldwide (WHO, 2018). In the short term, excessive alcohol consumption contributes to violence and abuse (Bellis et al., 2015; Laslett et al., 2010), while long term risks include cancer (Roswall \& Weiderpass, 2015) and liver disease (Mehta \& Sheron, 2019). To counter these harms, many countries publish guidelines setting a low-risk level of alcohol consumption, but there is considerable variation between different countries' recommendations of what represents low-risk drinking (Furtwaengler \& de Visser, 2013). This implies an objective understanding of what constitutes too much alcohol has yet to be achieved.

The United Kingdom (UK) Government advises that low-risk drinking constitutes 14 units (one unit $=10 \mathrm{ml}$ of alcohol) consumed over the course of a week (Department of Health, 2016). However, Wood et al.'s (2018) analysis of almost 600,000 drinkers suggests consuming only 12.5 units per week increases mortality risk. They also showed that exceeding the UK guideline of 14 units resulted in a lowered life expectancy of 1.6 years for men and 1.3 years for women. A systematic review that analysed data from 195 countries and 28 million participants (GBD 2016 Alcohol Collaborators, 2018) concluded that, 'the safest level of drinking is none' while acknowledging that this 'level is in conflict with most health guidelines'.

Relying on awareness of guidelines to reduce alcohol consumption is problematic. In the UK, drinkers of all ages exceed them regularly (Health and Social Care Information Centre, 2014; Knott, Scholes, \& Shelton, 2013). This is partly due to lack of knowledge: in one study, only a quarter of participants could accurately describe the guidelines (Buykx et al., 2018) and the amount of alcohol that constitutes a unit is frequently misjudged (De Visser \& Birch, 2012). 
Even when people possess accurate knowledge they do not necessarily drink within guidelines. Cooke et al. (2010)reported a non-significant correlation between knowledge of 'sensible drinking' and consumption in a sample of university students. People also ignore or disparage accurate information, and actively challenge the notion that such information is relevant for them. For example, UK drinkers viewed daily consumption guidelines as irrelevant because the recommendations ignored heavy weekend drinking, a widespread cultural practice (Lovatt et al., 2015). Those who exceed recommended limits often present themselves disingenuously to doctors, assuming they would be told to drink less if they were honest about their intake (Davies, Conroy, Winstock, \& Ferris, 2017).

A combination of low consensus on risk levels, and the seemingly unrealistic advice regarding unhealthy consumption can lead people to disregard or ignore existing guidelines. Instead, they often rely on their health beliefs when judging how much to drink. For this reason, researchers have investigated alcohol consumption using health belief models such as Ajzen's (1991) Theory of Planned Behaviour (TPB). The TPB assesses the degree to which attitudes, subjective norms and perceived behavioural control (PBC) contribute to intentions and behaviour. It has predicted young people's drinking successfully (Norman, Bennett, \& Lewis, 1998; Norman \& Conner, 2006) with PBC being a key predictor in some studies (e.g., French \& Cooke, 2012; Haydon, Obst, \& Lewis, 2016). However, Cooke et al.'s (2016) meta-analysis found an inconsistent relationship between PBC and alcohol consumption. Perceived behavioural control had a large, positive, relationship with light consumption (i.e., drinking within government guidelines), but a small, negative, relationship with heavy consumption (i.e., getting drunk). This research highlights the importance of people's beliefs regarding their perceived control, but also suggests that more needs to be known about people's experiences of control at different levels of consumption.

Recent qualitative research highlights the importance of addressing personal experiences of drinking alcohol, with an emphasis on what it is like to stay within perceived 
optimal levels of consumption. For example, Lovatt et al. (2015) used a lay epidemiology framework to assess adult drinkers' interpretations of UK guidelines. Such a framework focuses on the way that subjective experiences and media representations guide people's knowledge and beliefs about health and illness (Davison, Davey Smith \& Frankel, 1991). In Lovatt et al's (2015) study, participants said the guidelines were disconnected from their health beliefs and their subjective experiences of drinking, with one focus group reporting that 'their too much [i.e., the Government's] is not our too much'. Instead of counting units, they said that they counted drinks and relied on personal experiences of knowing how their bodies responded to alcohol.

Qualitative studies from a variety of nations have helped paint a nuanced picture of drinkers' experiences. Scottish mid-life adults were asked to describe the states they experienced when they drank (Lyons, Emslie, \& Hunt, 2014). Unlike Lovatt et al.'s (2015) participants, they did not count drinks but would notice the physical states associated with 'being in the zone' and associated with 'the point of no return' when they had consumed too much. Young Australians described how they hoped to feel when they drank alcohol and what they did to reach and to stay at those levels (Zajdow \& MacLean, 2014). They did not count units to monitor their drinking either, but they did attend to how they felt, aiming to maximize pleasure and to stay between 'the ideal state and the danger zone'. Young UK non-drinkers and moderate drinkers described their experiences of maintaining low-risk drinking patterns in social situations where higher levels of consumption were the cultural norm (Graber et al., 2016). They attempted to stay in the 'sweet spot', a positive experience that could transform into a negative one of being 'too drunk'. Similarly, young Italian drinkers spoke about the importance of alcohol to having fun in different social settings (Aresi \& Pedersen, 2016). They described desirable states that required purposeful action in order to maintain an 'acceptable level of intoxication' and not go 'beyond the limit'. Other young Italians attempted to strike a balance between getting the 'right kind of buzz' without reaching their tipping point (Beccaria, Petrilli, \& Rolando, 2015). 
Participants in the preceding studies allude to a potential limit of consumption that marks a point of no return and is associated with an experiential threshold of too much alcohol Despite the recent focus on peoples' experiences of drinking to optimal subjective levels, no research has directly addressed peoples' experiences of what it is like to approach and exceed their threshold of consuming too much alcohol. An elaboration of those states is the focus of the current research. The rationale for the design and analysis is founded on theoretical work on first-person experiential states that indicates experience is characterized by embodiment, prereflective self-consciousness, and by being socially embedded (Gallagher \& Zahavi, 2013; Zahavi, 2005, 2014)

Gallagher and Zahavi (2013) describe embodiment as a principle of experience (p.135) that exists along a continuum of positive-negative physical and affective states. Alcohol literature often refers to such states. Pleasure is an important motivation for students' drinking (Hutton, 2012; Webb, Ashton, Kelly, \& Kamali, 1996) and drinking for enhancement is common across countries and age groups (Cooper, 1994). Adults drink for enjoyment (Graber et al., 2016; Lovatt et al., 2015) to be calm and to feel 'just the right buzz' (Aresi \& Pedersen, 2016). These sensations are described as 'the pleasure zone' (Fry, 2011) but this zone is inherently unstable, open to change, and difficult to reach and maintain (Lyons et al., 2014; Zajdow \& MacLean, 2014). Drinkers are motivated to stay in an optimal zone to avoid the adverse physical states (e.g., feeling sick) and poor mood they fear will result from excessive consumption (Aresi \& Pedersen, 2016; de Visser, Wheeler, Abraham, \& Smith, 2013; Graber et al., 2016; Lyons et al., 2014).

The immediate, pre-reflective self-consciousness that is an intrinsic part of experience corresponds to a sense of 'self-as-subject' (Legrand, 2011; Zahavi, 2005). This ongoing awareness enables a person to know 'what it is like for me' to have this particular experience (Zahavi, 2014). While they are drinking, a person will know that it is they who is experiencing 'the buzz' and is happy, or who is stumbling and embarrassed. Drinkers have an intrinsic 
awareness of the ongoing effect of alcohol at lower levels of consumption and this can be used to monitor and alter the trajectory of one’s drunkenness (Katainen \& Rolando, 2015). People monitor drinking through the effect the drink is having on their bodies and they engage in strategies to keep in their sweet spot, such as switching drinks or slowing down their consumption (Aresi \& Pedersen, 2016; Lovatt et al., 2015). This implies agency and control, something that is fundamental to first-person experiences, whereby people feel themselves to be the intentional author of their actions (Gallagher \& Zahavi, 2013; Taylor, 1985).

Drinkers attempt to exert control over their experiential state. These attempts are described as a 'manageable loss of control' (Graber et al., 2016) 'controlled disinhibition' (Aresi \& Pedersen, 2016) 'intoxicated self-control' (Zajdow \& MacLean, 2014)and a 'controlled loss of control' (Measham, 2006). Restraint is exercised over the dis-inhibitory effects of alcohol but the level of control that people consider optimal varies across drinkers. On the one hand, Graber et. al.'s (2016) non-drinkers and moderate drinkers were aware of potential negative future states and wanted to be confident in making choices that would prevent the loss of control that could lead to bad experiences. On the other hand, other young and mid-life drinkers enjoyed testing the boundaries of their everyday state and experienced relief or excitement from diminished control (Engineer, Philips, Thompson, \& Nicholls, 2003; Lyons et al., 2014; Zajdow \& MacLean, 2014). At the extreme, loss of control can lead to blackouts and drinkers can become afraid of consuming excessive amounts in future (White, Signer, Kraus, \& Swartzwelder, 2004).

A person's drinking is not solely governed by their conscious intentions to exert or relinquish control. Social contexts also form potent guides for appropriate behavior (Gallagher \& Zahavi, 2013; Guignon, 2012) and are important in understanding people’s embodied experiences of drinking (MacAndrew \& Edgerton, 1969; MacLean, Pennay, \& Room, 2018; Zajdow \& MacLean, 2014). The first-person experiential perspective views an individual, the context they inhabit, and the people with whom they interact as intertwined rather than completely discrete entities. A person enters a pub already infused with a socially-constructed 
understanding of how to behave in that setting and their drinking is also infused with the behaviors of the people around them (Cooper, 2016; Dreyfus, 1991). To that extent, the individual embodies the context and the social groups therein and these combine with the drinker's conscious intentions to 'call forth' different drinking experiences (cf. Aresi \& Pedersen, 2016). Contextual and social norms can be internalized and associated with different experiences in regulating consumption to achieve optimal drinking states and to avoid transgressing norms of drunken presentation (Graber et al., 2016; Szmigin et al., 2008). However, this can be a balancing act. Many young adults believe that alcohol facilitates social interactions and is instrumental in forging group belonging (de Visser et al., 2013; Livingstone, Young, \& Manstead, 2011). They also believe that exceeding alcohol norms can interfere with meaningful communication and damage social reputation (MacLean et al., 2018).

\subsection{Aims:}

We investigated personal thresholds of too much alcohol. To do this, we used a theoretical framework for understanding first-person experiential states (Gallagher \& Zahavi, 2008; Zahavi, 2005, 2014). First, we determined whether participants had an intuitive sense of a threshold of too much alcohol. Those who did were expected to base that threshold on experiential embodied states rather than on a number, or units, of drinks. Participants' openended descriptions of (1) approaching and (2) exceeding a personal threshold of too much alcohol were analysed to determine the nature of the experience in relation to: positive or negative embodiment, by ongoing awareness of the effect of alcohol, by the ability to exert control, and by positive or negative views of self and social interactions.

\section{Method}

\subsection{Participants and procedure}


150 participants (97 women, 47 men, 6 non-binary) responded to an online survey about drinking attitudes and behaviours. Most respondents (84\%) were students and the average age was $23.3(\mathrm{SD}=5.5)$. The survey was promoted on university electronic notice boards and researchers' social media pages and delivered using Qualtrics software. The study was approved by XXX University Research Ethics Committee.

\subsection{Measures}

Alcohol consumption was assessed using the Alcohol Use Disorders Identification Test (AUDIT) (Babor, Higgins-Biddle, Saunders, \& Monteiro, 2001). The 10-item questionnaire measured alcohol consumption and harms as a score from 0-40 (0-7= low risk; 8-15= increasing risk; $16-19=$ higher risk; $20+=$ possible dependence). This enabled an assessment of the categories of drinker in the sample.

Experiential thresholds were assessed through participants' written responses to questions in separate essay boxes on the online survey. There was no word limit or restriction placed on the answers. Initially, participants were asked whether they: had an intuitive sense of what would constitute too much alcohol (either in terms of the way in which the drink makes you feel or in terms of an absolute amount of alcohol)? If they responded affirmatively, they were asked to: describe how you established your own personal intuitive sense of too much and whether this has changed over time. Following this, they were asked whether it was: something that remains consistent across different situations or does it fluctuate according to the situation?

Nagel (1974) described the phenomenal structure of experience as a description of 'what it is like' to experience something. Our participants were asked to: Imagine the following experience: Imagine that you are actually drinking and that you approach, but do not exceed, your own personal intuitive sense of 'too much'. Can you describe the feelings, thoughts, and just generally what it is like to approach, but not exceed, your own personal sense of too much. Finally, they did the same thing for the experience of exceeding their sense of too much alcohol. 


\subsection{Analysis}

This paper used a mixed methods approach. Thematic analysis (Braun \& Clarke, 2006) was guided by a deductive, theory driven process (Gallagher \& Zahavi, 2008; Zahavi, 2005, 2014). Participants' accounts were examined for statements corresponding to experiences revealing: (1) embodiment in the form of physical and affective states (2) an ongoing awareness of the effect of alcohol (3) control (4) reflections on self and (5) reflections on social interactions. All descriptions of the threshold of too much alcohol were read and reread to ensure that codes were also grounded in participants' statements and reflected their experiences. The first and third authors independently coded 15 participants' responses to all questions. Any differences in coding were discussed with reference to theory, previous alcohol research and the participants' experience, and the coding revised to reflect agreement. The first author then coded the remaining 135 participants' accounts. The third author assessed a further sample of 15 participants' accounts of all questions to ensure that coding remained consistent across the corpus. Original accounts were reread in light of the analytic interpretations to ensure that participant descriptions were represented accurately. Descriptive statistics and chisquare were used to compare participants' drinking behaviours and the frequency of codes applied to their accounts.

\section{Results}

\subsection{Do participants have an intuitive sense of too much alcohol?}

An intuitive sense of too much alcohol was established by 149 of the 150 participants. This was founded on previous drinking experiences, with 119 (80\%) participants referring to physical and affective states as important in determining their threshold (see Table 1). For physical states, 101 (68\%) descriptions referred only to negative physical states (e.g., stumbling), two referred only to positive physical states (e.g., a tipsy buzz), and 14 (9\%) referred to both negative and positive states. For affective states, $62(42 \%)$ referred only to 
negative affective states (e.g., embarrassed), eight (5\%) referred only to positive affective states (e.g., happy), and nine (6\%) referred to both negative and positive states.

\section{[Insert Table 1]}

Distinct amounts (e.g., 5-6 pints), and distinct types (e.g., spirits) of alcohol appeared in $32(21 \%)$ and $16(11 \%)$ descriptions respectively. These drinks illustrated what would lead participants to exceed their threshold and to lose control. Only two people referred to government guidelines as informing their sense of too much alcohol (e.g., 'through gaining knowledge of government guidelines and personal experience' P107, female, 26 yrs), and only six people referred to long-term health as contributing to their intuitive level of too much (e.g., 'I understand the health risks of too much alcohol' P72, female, 19 yrs).

In terms of stability, 36 (24\%) participants said that their sense of too much alcohol stayed the same (e.g., 'it's based on my past experiences and it hasn't changed', P137, male, $24 y r s)$ and 46 (31\%) indicated that it had changed over time (e.g., 'largely because the amount I drink has decreased, leading me to get drunk with less alcohol', P1, male, 23yrs). Nineteen (13\%) participants mentioned a pre-existing internal state (e.g., having eaten) influencing their sense of too much alcohol. Seventy-eight (52\%) participants mentioned an external factor (e.g., where a person was) as being an influence. A lower threshold was considered more appropriate at family functions or work events where participants were concerned about how they would be judged (e.g., 'too much for a family dinner would be less than too much when I'm clubbing with friends. I'd feel more comfortable being more drunk in a setting where it's more acceptable' P149, male, 19yrs). The mean AUDIT score for the sample was 10.48 (SD=6.25); $38.1 \%$ of participants were categorised as 'low risk', $42.9 \%$ as 'increasing risk', $9.5 \%$ as 'higher risk', and 9.5\% as 'possible dependence'.

\subsection{Approaching the threshold of too much alcohol}




\subsubsection{Physical and affective states}

Approaching the threshold was described as a physical and/or affective state by 139/150, (93\%), participants. Seventy-five per cent of the overall sample described their experience of approaching their threshold at the extremes of the positive-negative continuum of physical and affective states. At one extreme, 61 participants (41\%) described the approach as an entirely negative embodied state (e.g., 'nausea and anxiety' P102, female, 22yrs). At the other extreme, 51 participants (34\%) described the approach as an entirely positive embodied state (e.g., 'relaxed and enjoying myself' P17, female, 21yrs). A further 9 (6\%) participants experienced the approach as predominantly (but not exclusively) negative, 11 (7\%) participants experienced an equal balance between negative and positive physical and affective states, and 7 (5\%) participants experienced the approach as predominantly (but not exclusively) positive. The remaining $11(7 \%)$ participants provided accounts that had no mention of physical or affective states at all. There was no significant association between participant gender and descriptions of physical and affective states, $\chi^{2}=1.64, \mathrm{p}=0.44$, ns.

The remaining analyses focus on contrasting the descriptions of those who experienced an entirely negative embodied approach (henceforth, Group 1) with those who experienced an entirely positive embodied approach (henceforth, Group 2). These groups constituted the majority of participants and were completely distinct phenomenological states. Analysis of AUDIT scores revealed no significant differences between Group $1(M=10.9 ; S D=6.77)$ and Group $2(M=10.16 ; S D=5.31)$, with each group's average falling within the category of 'increasing risk.'

[Insert Table 2]

\subsubsection{Ongoing awareness}


Those experiencing an entirely negative embodied approach (Group 1: 55/61) were more likely than those experiencing an entirely positive embodied approach (Group 2: 27/51) to report being aware of the ongoing effect of alcohol (e.g., Group 1: 'I am aware myself that I am drinking too much and it does not feel very nice to be approaching that point' P7, female, 20 yrs; Group 2: 'I'm always aware of how drunk I am and know when I'm feeling good' P77, female, 21yrs), $\chi^{2}=19.63, \mathrm{p}<.01$. Group $1(42 / 61)$ were also more likely than Group $2(12 / 51)$ to report being aware of potential future adverse states (e.g., Group 1: 'I usually start thinking about how I feel when I'm too drunk or hungover and realise that I might be heading that way and want to avoid it' P42, female, 28yrs; Group 2: 'I know if I have that next drink I'm gonna be spinning and on the bathroom floor and that's not nice!' P128, male, 27yrs) $\chi^{2}=22.85, \mathrm{p}<.01$.

\subsubsection{Experiencing control and strategies for preventing loss of control}

A significantly greater proportion of Group 1 participants (33/61) than Group 2 participants (11/51) were concerned about losing control (e.g., Group 1: 'I start to feel out of control and say things I shouldn't' P65, female, 20yrs; Group 2: 'I would feel quite in control as I would know that I haven't had too much to drink' P51, female, 28yrs), $\chi^{2}=12.32, \mathrm{p}<.05$. Group $1(26 / 61)$ were also more likely than Group $2(11 / 51)$ to report having a strategy for dealing with drinking too much (e.g., Group 1: 'I remove myself from that drinking environment so as to avoid the social pressures of stopping drinking before any others you are with want to' P3, male, 21yrs; Group 2: 'I tend to drink more water if I'm approaching too much' P124, female, 29yrs), $\chi^{2}=14.66, \mathrm{p}<.05$.

\subsubsection{Perceptions of self and social interactions}

Group 1 were less likely (00/61) than Group 2 (19/51) to describe the self positively (e.g., Group 2: 'I feel entirely aware of myself, but with a more positive outlook' P18, male, 20yrs) $\chi^{2}=22.33, \mathrm{p}<.05$. Group 1 were also less likely (02/61) than Group $2(19 / 51)$ to report positive social interactions (e.g., Group 1: 'I would not be enjoying people’s company any more' 
P99, female, 24yrs; Group 2: 'I would be feeling more conversational and less inhibited' P111, female, 23yrs) $\chi^{2}=21.05, \mathrm{p}<.05$.

\subsection{Exceeding the threshold of too much alcohol}

Participants' accounts revealed that 147 (98\%) of them had exceeded their threshold of too much alcohol, and that three had not.

\subsubsection{Physical and affective states}

Exceeding the threshold of too much alcohol was described by 144 (96\%) of the participants as a physical and/or affective state. The other six made no mention of physical or affective states. The majority of participants $(130 / 150,87 \%$ of the entire sample) described the experience of exceeding their threshold as an entirely negative physical and affective state. Recall that Group 1 experienced the approach to their threshold as an entirely negative embodied state and Group 2 had experienced the approach to their threshold as an entirely positive embodied state.

Exceeding the threshold was described as an entirely negative embodied state for participants of each group (Group 1: 52/61, 85\%; Group 2: 45/51, 88\%), $\chi^{2}=0.04, \mathrm{p}=0.84$, ns. See Table 2 for descriptions of the transition from approaching to exceeding the threshold.

\subsubsection{Ongoing awareness}

When exceeding their threshold, there were no longer differences between Group 1 (30/61) and Group $2(24 / 51)$ in being aware of the ongoing effect of alcohol $\left(\chi^{2}=0.05, p=0.83, n s\right)$. Among Group 1 participants, fewer reported an ongoing awareness in their accounts of exceeding the threshold compared to their accounts of approaching the threshold $\chi^{2}=24.24, \mathrm{p}<$ .01. There were also no differences between Group 1 (31/61) and Group 2 (27/51) in awareness of potential future adverse states, $\chi^{2}=0.05, p=0.82$. Relative to approaching their thresholds, fewer participants of Group 1 reported an awareness of potential negative states $\left(\chi^{2}\right.$ 
$=4.13, \mathrm{p}<.05$ ) and more participants of Group 2 reported an awareness of potential negative states $\left(\chi^{2}=9.34, \mathrm{p}<.05\right)$.

\subsubsection{Experiencing control and strategies for preventing loss of control}

Similar proportions of Group 1 (50/61) and Group 2 (45/51) felt they were not in control when exceeding their threshold (e.g., Group 1: 'I would feel out of control and vulnerable' P43, female, 22yrs: Group 2: ‘I feel completely out of control ... I do not enjoy this feeling at all’ P122, female, 23yrs), $\chi^{2}=0.84, p=0.35$, ns. There were no longer differences between Group $1(11 / 61)$ and Group $2(7 / 51)$ in reporting a strategy for dealing with drinking too much, $\chi^{2}=0.38, p=.54$. Significantly fewer Group 1 participants reported a strategy when exceeding their threshold than when approaching their threshold, $\chi^{2}=8.60, \mathrm{p}=.01$, (there were no differences for Group 2 relative to their approach).

\subsubsection{Perceptions of self and social interactions}

There were no differences between Group $1(0 / 61)$ and Group 2 (2/51) in describing the self positively, $\chi^{2}=0.06, p=0.80, n s$, or differences between Group $1(3 / 61)$ and Group $2(3 / 51)$ in describing positive social interactions, $\chi^{2}=0.05, p=0.82$, ns. Relative to their experience of approaching their threshold, there were no differences on either of these measures for participants of Group 1, but there were significantly fewer Group 2 participants describing self and interactions positively, $\chi^{2} \mathrm{~s}>14.80$, ps $<.01$.

\section{Discussion}

\subsection{Summary of findings}

Previous research alluded to drinkers constructing a threshold that marked an experiential danger zone (e.g., Aresi \& Pedersen, 2016; Graber et al., 2016, Lyons et al., 2014). The current research focused specifically on the existence, and nature, of that threshold. It used 
an a priori first-person experiential framework (Gallagher \& Zahavi, 2008; Zahavi, 2005, 2014) to elucidate the key factors intrinsic to approaching and exceeding a threshold of too much alcohol. Participants had an intuitive sense of what too much alcohol meant to them. It was a threshold that had been learned over time and was based on physical and affective states rather than external guidelines. One group described the approach to the threshold as an entirely positive embodied state, and another group described it as an entirely negative embodied state. These two groups' experiences of approaching their thresholds also differed in terms of awareness, control, perceptions of self, and the quality of their social interactions. In contrast, exceeding the threshold was uniformly experienced as a negative embodied state, characterised by loss of awareness, loss of control, negative self-perception, and low quality social interactions.

\subsection{Establishing personal thresholds}

Government guidelines, long-term health (de Visser et al., 2013), and number of drinks (Lovatt et al. 2015) did not figure strongly in participants' descriptions of what informed their thresholds of too much alcohol. Instead, their thresholds were established through recognizing previous negative states. These were predominantly embodied experiences that involved losing physical control, suggesting their threshold was forged at levels where alcohol had previously incapacitated the drinker. This demonstrates a disconnect between medical conceptions of risk and the experiences that people call on to gauge when to stop drinking. Medically, Woods et al. (2018) suggested 12.5 units per week as a suitable threshold, beyond which drinkers can expect long-term damage. The Global Burden of Disease Alcohol Collaborators (2018) suggested that any level of alcohol consumption should be considered unsafe. Experientially however, participants constructed a threshold that corresponded to an emphatic loss of control, suggesting levels of consumption far in excess of those recommendations, and a focus on short term risks of drinking too much alcohol. 
Medical guidelines also imply consumption should remain stable over time and situation. In contrast, participants' experiential thresholds were not anchored permanently. They were dynamic, moving according to internal states and external contexts. Internally, participants' knowledge of their embodied states improved with drinking experience. Hunger would produce a lower threshold. Regular drinking would induce a physical tolerance where the threshold would move to higher levels, and irregular drinking would move the threshold to lower levels. Contextually, participants' thresholds were influenced by norms for acceptable levels of drunkenness, their comfort for self-presentation, and their concerns for being vulnerable. These findings correspond with other research that highlighted the power of personal experience and situational norms in determining appropriate levels of consumption (Aresi \& Pedersen, 2016; MacLean et al., 2018; Szmigin et al., 2008) Together, these data suggest that an intuitive and experiential personal threshold for too much alcohol is a widespread phenomenon that differs markedly from authoritative recommendations.

\subsection{Approaching the threshold}

Having determined how people constructed their thresholds and whether these were consistent over time and situations, we investigated the subjective experience of drinking when approaching and exceeding those thresholds. Nearly all participants (93\%) described approaching their threshold as an embodied, physical and affective state. These experiences were characterised by rich accounts, with $75 \%$ of participants describing states at either extreme of the positive-negative continuum outlined by Gallagher and Zahavi (2008). Drinkers in previous research have implied that thresholds exist that represent a state of being 'too drunk' (Graber et al. 2016) and at which point they would lose control (Aresi \& Pedersen, 2016). Our Group 1 participants were already experiencing entirely negative physical and affective states prior to reaching their threshold (e.g., impaired vision and fear). For them, being just below the experiential danger zone was a distinctly unappealing state that was fraught with warnings. In contrast, our Group 2 participants experienced entirely positive physical and 
affective states (e.g., relaxed and happy), and being just below their threshold was associated with the appealing experiential states characteristic of optimal levels of consumption (cf. Graber et al., 2016; Lyons et al., 2014).

More participants of Group 1 than of Group 2 were aware of the ongoing effect of alcohol and of the likely debilitating short-term consequences of continuing to drink (e.g., being sick and hungover). Previously, a range of different drinkers have described their attempts to retain manageable levels of control in order to keep them in the desired zone of pleasurable experiences (e.g., Measham, 2006; Zajdow \& MacLean, 2014). In the current research, Group 1 drinkers were already tipping into an uncontrollable state. They did not feel they had lost control completely but were concerned that they would if they did not act to counter the effects of alcohol. As with previous research on optimal levels of alcohol consumption (e.g., Zajdow \& MacLean, 2014), these findings suggest that drinkers are acutely aware that the embodied state they seek is inherently unstable. The differing experiences reported by the two groups correspond with Cooke et al.'s (2016) findings that PBC related positively to light consumption but not to heavy consumption. Group 1 reported anxiety about drinking too much, monitored their feelings, and worried about getting out of control. They would probably be happiest to drink within government guidelines, and stay in control and distant from their threshold. In contrast, Group 2 wanted to lose control and saw that state as an inherent part of their pleasure.

Although people may drink to maximise pleasure, the exhilaration of that pleasure is perilous in that it can transform into a damaging state relatively quickly. Participants attempted to balance the extra-ordinary state of pleasure that alcohol can facilitate with the extra-ordinary pain that can result from exceeding their threshold. More of Group 1 than Group 2 expressed a concern about losing control, but more participants of Group 1 also expressed agency in having a deliberate strategy to take them off a drunken path that would prove detrimental to their wellbeing (cf Vihvelin, 2013). These participants would stop drinking, switch to water, or remove themselves from the situation entirely. This is comparable to Haydon et al.'s(2016) results 
where participants of higher perceived control would be able to withstand the desire to drink and/or counter a situational pressure to consume more alcohol. In keeping with those findings, our participants did not simply demonstrate impressive conscious intentions to exert control and drink less. Their accounts also illustrate the degree to which participants were aware that the contextual and peer norms infused their own drinking behavior (cf. Aresi \& Pedersen, 2016; Haydon et al., 2016). In order to change behavior, they left their social group and the context. Other Group 1 participants were similarly aware that they could attempt to halt the progressive loss of control and forestall further nausea and severe hangovers, yet they experienced internal conflict whereby their desire to continue drinking overrode their decision to stop drinking. These accounts revealed an acknowledgement of being intentional authors of their actions (cf. Gallagher \& Zahavi, 2008), yet they ploughed on, ignoring the sensible routes that were still in their control to take. This conflict is notable in light of the degree to which people are said to be motivated to avoid exceeding their threshold (e.g., Zajdow \& MacLean, 2014) but is consistent with binge drinkers' impaired decision-making, poor impulse control (Townshend, Kambouropoulos, Griffin, Hunt, \& Milani, 2014) and impaired executive functioning (e.g., Tomassini et al., 2011). People's motivation to act in a manner that avoids imminent harm dissipates when the drinker is close to their threshold.

Fewer of Group 1 than Group 2 related positively to themselves in the approach to their threshold. Group 2 drinkers were similar to participants in previous studies on optimal levels of consumption in describing a powerful psychological state of confidence, dis-inhibition and feeling free from others' judgements (e.g., Engineer et al., 2003; Graber et al., 2016; Lyons et al., 2014; Zajdow \& MacLean, 2014). Group 1 participants described potential shame and embarrassment at the hands of others and were not enjoying people's company. To view oneself as shameful is to take the position of 'self-as-object' (Legrand, 2011; Zahavi, 2005) where a selfreferential narrative reveals what a person thinks their actions 'say about me' (Gallagher \& Zahavi, 2008). Becoming too drunk involves that person being out of kilter with the social norms they have internalised for that setting (cf. Dreyfus, 1997). This can be an alienating and 
sometimes embarrassing experience that reduces self-esteem (Graber et al., 2016). However, some drinkers relish the experience of temporarily acting beyond the boundaries of their normal self when intoxicated (Lyons et al., 2014; Zajdow \& MacLean, 2014). Group 2's participants experienced fun, enjoyable conversations and positive social interactions. The distinctly different nature of Group 1 and Group 2 participants' approach to the threshold implied that there are varying gaps between people's sweet spots and what constitutes a point of no return. Group 1 appeared already to have moved beyond the sweet spot to inhabit a vulnerable physical and psychological state. In comparison, Group 2 appeared to inhabit an enviable phenomenological state. However, when their threshold was exceeded their enviable state changed dramatically.

\subsection{Exceeding the threshold}

Nearly all participants (98\%) had exceeded their threshold for too much alcohol, an experience that was an entirely negative embodied state for $87 \%$ of the sample. The experiential differences that were evident between Group 1 and Group 2 in their approach to the threshold disappeared when they exceeded the threshold. This was an entirely negative embodied state for both groups. Some participants were aware that they were drunk but no longer cared about the consequences of being in that state. Others had blacked out completely, losing the ability to report details regarding their pre-reflective awareness of their experiences (cf. White et al., 2004). In exceeding the threshold there was an extreme loss of control for both Group 1 and Group 2. During their approach to the threshold, Group 1 participants were losing control. To that extent, their further loss of control appeared to be a continuation of a descent that was already in process. In contrast, Group 2 participants' approach to the threshold had been marked far less by loss of control. They appeared to have been riding a positive wave until they experienced a stark crash in control upon exceeding their threshold.

Crossing that point of no return resulted in both groups feeling ill, disoriented, and experiencing poor mood. They could also become vulnerable through their inability to take care 
of themselves. Over the next day or two they would have a severe hangover and in the longer term could experience regret and embarrassment. They carried those experiences to the next drinking events and bore them in mind. Reflecting upon one's drinking experiences and carrying that knowledge to future occasions has been noted in young adults' attempts to avoid being seen as disgusting or repulsive by their peers (MacLean et al. 2018). As a whole, these findings strongly suggest that drinking around the threshold of too much alcohol is not simply a first-person experiential phenomenon resulting from conscious intentions; it is an experiential state that is inter-relational and contextually embedded (Graber et al., 2016; Lyons et al., 2014).

\subsection{Limitations}

These findings must be considered alongside the limitations of the study. All responses were retrospective and the mean AUDIT score was within the 'increasing risk' range. Future work could examine whether the objective consumption level of Group 1's threshold is actually higher than that of Group 2. Group 1 described already feeling ill and out of control during their approach, whereas Group 2 did not. It is possible that there was a difference in the objective amount of alcohol that the threshold for too much alcohol represents for each of these groups even though there was no difference in AUDIT scores.

The current sample was relatively young and largely student-based. This age and environment are often associated with exploration of alcohol and social events and with particular drinking norms (Graber et al., 2016). There will likely be a different foundation for thresholds in other age groups (e.g., middle aged people may establish a threshold that still enables them to work effectively the next day or to look after children with a clear mind, see Lyons et al., 2014). Therefore, older people's concept of their threshold may change according to wider social responsibilities and not be oriented towards complete loss of control.

\subsection{Implications and conclusions}


Notwithstanding the limitations, this study is the first to focus on the experiential threshold of too much alcohol, and also uses a theoretical framework to guide the design and the analysis of these experiences. We also examined the transition from one state (approach) to another (exceed), which is novel because most research does not address progression between different states. Participants monitored their embodied state and assessed the degree of control they felt they had and anticipated the likelihood of descending into an incoherent and nauseas state. This level of attention and anticipation of action speaks to a state that is subject to active management, implying the potential for personal agency and an opportunity to construct interventions to influence people towards less harmful consumption. The more a person seeks a sweet spot close to their threshold of too much, the more their body will adapt to the alcohol, and the further their threshold will move from safe levels of consumption (Tabakoff, Cornell, \& Hoffman, 1986). People who experience entirely negative embodiment when approaching their threshold may be amenable to interventions as their bodies are already strongly signalling them to stop. People who experience entirely positive embodiment may be less willing to break their flow, but it might be even more important for them to curtail their drinking. Given the social nature of many of the participants' accounts of drinking, further research could also explore how members of Group 1 and Group 2 influence each other on a night out. Imagine someone in Group 1, witnessing the joy of those clearly in Group 2 who are ebullient, in control and interacting well with others. How might that Group 1 person change their experiential state to match that of their peer? Is the answer to drink more? A naturalistic study within a bar-lab setting may be amenable to addressing such research questions.

Finally, these results highlight the important temporal considerations that underpin drinkers' experiences and government guidelines. Participants were temporally oriented to the present and also to the immediate future and attempted to balance positive and negative experiences. As with de Visser et al.'s (2013) participants, they had no concern for long-term health consequences. Medically grounded guidelines are temporally oriented to the present (e.g., safety), the short-term future (e.g., damage from severe hangovers), the medium-term 
future (e.g., diabetes), and the long-term future (e.g., early death). Therefore there is a temporal disjunction between the experiences of the drinker and authoritative recommendations for how much to drink. People construct their threshold of too much alcohol on judgements of whether their night will end badly rather than whether their life will end early (cf. Woods et al. 2018; Global Burden of Disease Alcohol Collaborators, 2018). The challenge is to find a way of incorporating the increasingly robust medical findings into people's lived experiences of drinking. Many people are intimately aware that excessive drinking would be likely to leave them feeling physically incapable, psychologically distressed, to lose control of their actions, to have a diminished sense of who they are, and to interact poorly with others. That is what it is like to exceed their threshold of too much alcohol, and yet the majority of people who are aware of what that experience is like, will do it again. 


\section{References}

Ajzen, I. (1991). The theory of planned behavior. Organizational Behavior and Human Decision Processes, 50(2), 179-211.

Aresi, G., \& Pedersen, E. R. (2016). 'That right level of intoxication': A Grounded Theory study on young adults' drinking in nightlife settings. Journal of Youth Studies, 19(2), 204-220. doi: 10.1080/13676261.2015.1059931

Babor, T., Higgins-Biddle, J. C., Saunders, J. B., \& Monteiro, M. G. (2001). The Alcohol Use Disorders Identification Test, Guidelines for Use in Primary Care (2nd edition ed.). Geneva: World Health Organization.

Beccaria, F., Petrilli, E., \& Rolando, S. (2015). Binge drinking vs. drunkenness. The questionable threshold of excess for young Italians. Journal of Youth Studies, 18(7), 823-838. doi: $10.1080 / 13676261.2014 .992321$

Bellis, M. A., Quigg, Z., Hughes, K., Ashton, K., Ferris, J. A., \& Winstock, A. (2015). Harms from other people's drinking: an international survey of their occurrence, impacts on feeling safe and legislation relating to their control. Bmj Open, 5(12). doi: e01011210.1136/bmjopen-2015-010112

Braun, V., \& Clarke, V. (2006). Using thematic analysis in psychology. Qualitative Research in Psychology, 3(2), 77-101.

Buykx, P., Li, J., Gavens, L., Hooper, L., Gomes de Matos, E., \& Holmes, J. (2018). Self-Reported Knowledge, Correct Knowledge and use of UK Drinking Guidelines Among a Representative Sample of the English Population. Alcohol and Alcoholism. doi: 10.1093/alcalc/agx127

Cooke, R., Dahdah, M., Norman, P., \& French, D. P. (2016). How well does the theory of planned behaviour predict alcohol consumption? A systematic review and meta-analysis. Health Psychology Review, 10(2), 148-167. doi: 10.1080/17437199.2014.947547

Cooke, R., French, D. P., \& Sniehotta, F. F. (2010). Wide variation in understanding about what constitutes 'binge-drinking'. Drugs-Education Prevention and Policy, 17(6), 762-775. doi: $10.3109 / 09687630903246457$

Cooper, M. (2016). Existential therapies: Sage.

Cooper, M. L. (1994). Motivations for alcohol use among adolescents: Development and validation of a four-factor model. Psychol Assess, 6. doi: 10.1037/1040-3590.6.2.117

Davies, E. L., Conroy, D., Winstock, A. R., \& Ferris, J. (2017). Motivations for reducing alcohol consumption: An international survey exploring experiences that may lead to a change in drinking habits. Addictive Behaviors, 75, 40-46. doi: http://dx.doi.org/10.1016/j.addbeh.2017.06.019

De Visser, R. O., \& Birch, J. D. (2012). My cup runneth over: Young people's lack of knowledge of low-risk drinking guidelines. Drug and Alcohol Review, 31(2), 206-212. doi: 10.1111/j.1465-3362.2011.00371.x

de Visser, R. O., Wheeler, Z., Abraham, C., \& Smith, J. A. (2013). “Drinking is our modern way of bonding": Young people's beliefs about interventions to encourage moderate drinking. Psychology \& Health, 28(12), 1460-1480. doi: 10.1080/08870446.2013.828293

Department of Health. (2016). UK Chief Medical Officers' Alcohol Guidelines Review Summary of the proposed new guidelines. Retrieved 7 June 2016, from https://www.gov.uk/government/uploads/system/uploads/attachment data/file/489 795/summary.pdf

Dreyfus, H. L. (1991). Being-in-the-world: A commentary on Heidegger's Being and Time, Division I: Mit Press.

Engineer, R., Philips, A., Thompson, J., \& Nicholls, J. (2003). Drunk and disorderly: a qualitative study of binge drinking among 18-24-year-olds (Home Office Research Study 262 ed.). London: Home Office Research, Development and Statistics Directorate. 
French, D. P., \& Cooke, R. (2012). Using the theory of planned behaviour to understand binge drinking: The importance of beliefs for developing interventions. British Journal of Health Psychology, 17, 1-17. doi: 10.1111/j.2044-8287.2010.02010.x

Fry, M. L. (2011). Seeking the pleasure zone: understanding young adult's intoxication culture. Australas Mark J, 19. doi: 10.1016/j.ausmj.2010.11.009

Furtwaengler, N. A. F. F., \& de Visser, R. O. (2013). Lack of international consensus in low-risk drinking guidelines. Drug and Alcohol Review, 32(1), 11-18. doi: 10.1111/j.14653362.2012.00475.x

Gallagher, S., \& Zahavi, D. (2013). The phenomenological mind: Routledge.

GBD 2016 Alcohol Collaborators. (2018). Alcohol use and burden for 195 countries and territories, 1990\&\#x2013;2016: a systematic analysis for the Global Burden of Disease Study 2016. The Lancet, 392(10152), 1015-1035. doi: 10.1016/S0140-6736(18)31310-2

Graber, R., de Visser, R. O., Abraham, C., Memon, A., Hart, A., \& Hunt, K. (2016). Staying in the 'sweet spot': A resilience-based analysis of the lived experience of low-risk drinking and abstention among British youth. Psychology \& Health, 31(1), 79-99. doi: 10.1080/08870446.2015.1070852

Guignon, C. (2012). Becoming a person: Hermeneutic phenomenology's contribution. New Ideas in Psychology, 30(1), 97-106. doi: 10.1016/j.newideapsych.2009.11.005

Haydon, H. M., Obst, P. L., \& Lewis, I. (2016). Beliefs underlying Women's intentions to consume alcohol. BMC Womens Health, 16, 36. doi: 10.1186/s12905-016-0317-3

Health and Social Care Information Centre. (2014). Statistics on Alcohol England, 2014. London: Lifestyle Statistics, Health and Social Care Information Centre.

Hutton, F. (2012). Harm reduction, students and pleasure: An examination of student responses to a binge drinking campaign. International Journal of Drug Policy, 23(3), 229-235. doi: 10.1016/j.drugpo.2011.10.001

Katainen, A., \& Rolando, S. (2015). Adolescents' understandings of binge drinking in Southern and Northern European contexts - cultural variations of 'controlled loss of control'. Journal of Youth Studies, 18(2), 151-166. doi: 10.1080/13676261.2014.933200

Knott, C. S., Scholes, S., \& Shelton, N. J. (2013). Could more than three million older people in England be at risk of alcohol-related harm? A cross-sectional analysis of proposed agespecific drinking limits. Age Ageing, 42. doi: 10.1093/ageing/aft039

Laslett, A. M., Catalano, P., Chikritzhs, T., Dale, C., Doran, C., Ferris, J. A., ... Matthews, S. (2010). The range and magnitude of alcohol's harm to others. Fitzroy, Victoria: AER Centre for Alcohol Policy Research, Turning Point Alcohol and Drug Centre, Eastern Health.

Legrand, D. (2011). Phenomenological dimensions of bodily self-consciousness: na.

Livingstone, A. G., Young, H., \& Manstead, A. S. R. (2011). We Drink, Therefore We Are: The role of group identification and norms in sustaining and challenging heavy drinking culture. Group Processes \& Intergroup Relations, 14(5), 637-649. doi: $10.1177 / 1368430210392399$

Lovatt, M., Eadie, D., Meier, P. S., Li, J., Bauld, L., Hastings, G., \& Holmes, J. (2015). Lay epidemiology and the interpretation of low-risk drinking guidelines by adults in the United Kingdom. Addiction, 110(12), 1912-1919. doi: 10.1111/add.13072

Lyons, A. C., Emslie, C., \& Hunt, K. (2014). Staying 'in the zone' but not passing the 'point of no return': embodiment, gender and drinking in mid-life. Sociology of Health \& Illness, 36(2), 264-277. doi: 10.1111/1467-9566.12103

MacAndrew, C., \& Edgerton, R. B. (1969). Drunken comportment: A social explanation. Oxford: Aldine

MacLean, S., Pennay, A., \& Room, R. (2018). 'You're repulsive': Limits to acceptable drunken comportment for young adults. International Journal of Drug Policy, 53, 106-112.

Measham, F. (2006). The new policy mix: Alcohol, harm minimisation, and determined drunkenness in contemporary society. International Journal of Drug Policy, 17(4), 258268. doi: 10.1016/j.drugpo.2006.02.013

Mehta, G., \& Sheron, N. (2019). No safe level of alcohol consumption \&\#x2013; Implications for global health. Journal of Hepatology. doi: 10.1016/j.jhep.2018.12.021 
Nagel, T. (1974). What is it like to be a bat? Philos. Rev., 83, 435-450.

Norman, P., Bennett, P., \& Lewis, H. (1998). Understanding binge drinking among young people: an application of the Theory of Planned Behaviour. Health Educ Res, 13(2), 163-169.

Norman, P., \& Conner, M. (2006). The theory of planned behaviour and binge drinking: Assessing the moderating role of past behaviour within the theory of planned behaviour. British Journal of Health Psychology, 11, 55-70. doi: 10.1348/135910705x43741

Peele, S., \& Brodsky, A. (2000). Exploring psychological benefits associated with moderate alcohol use: a necessary corrective to assessments of drinking outcomes? Drug and Alcohol Dependence, 60(3), 221-247. doi: 10.1016/s0376-8716(00)00112-5

Ronksley, P. E., Brien, S. E., Turner, B. J., Mukamal, K. J., \& Ghali, W. A. (2011). Association of alcohol consumption with selected cardiovascular disease outcomes: a systematic review and meta-analysis. $B M J, 342$, d671. doi: $10.1136 /$ bmj.d671

Roswall, N., \& Weiderpass, E. (2015). Alcohol as a risk factor for cancer: existing evidence in a global perspective. J Prev Med Public Health, 48(1), 1-9. doi: 10.3961/jpmph.14.052

Szmigin, I., Griffin, C., Mistral, W., Bengry-Howell, A., Weale, L., \& Hackley, C. (2008). Re-framing 'binge drinking' as calculated hedonism: Empirical evidence from the UK. International Journal of Drug Policy, 19(5), 359-366. doi: 10.1016/j.drugpo.2007.08.009

Tabakoff, B., Cornell, N., \& Hoffman, P. L. (1986). Alcohol tolerance. Annals of emergency medicine, 15(9), 1005-1012.

Taylor, C. (1985). Human agency and language.

Townshend, J. M., Kambouropoulos, N., Griffin, A., Hunt, F. J., \& Milani, R. M. (2014). Binge Drinking, Reflection Impulsivity, and Unplanned Sexual Behavior: Impaired DecisionMaking in Young Social Drinkers. Alcoholism: Clinical and Experimental Research, 38(4), 1143-1150. doi: 10.1111/acer.12333

Vihvelin, K. (2013). Causes, laws, and free will: Why determinism doesn't matter: Oxford University Press.

Webb, E., Ashton, C. H., Kelly, P., \& Kamali, F. (1996). Alcohol and drug use in UK university students. Lancet, 348(9032), 922-925. doi: 10.1016/s0140-6736(96)03410-1

White, A. M., Signer, M. L., Kraus, C. L., \& Swartzwelder, H. S. (2004). Experiential aspects of alcohol-induced blackouts among college students. Am J Drug Alcohol Abuse, 30(1), 205224.

WHO. (2018). Global status report on alcohol and health 2018. Geneva: World Health Organisation.

Wood, A. M., Kaptoge, S., Butterworth, A. S., Willeit, P., Warnakula, S., Bolton, T., . . Davey Smith, G. (2018). Risk thresholds for alcohol consumption: combined analysis of individualparticipant data for $599 \& \# \mathrm{x} 2008 ; 912$ current drinkers in 83 prospective studies. The Lancet, 391(10129), 1513-1523. doi: 10.1016/S0140-6736(18)30134-X

Zahavi, D. (2005). Subjectiviy and Selhood: Cambridge, MA: The MIT Press.

Zahavi, D. (2014). Self and other: Exploring subjectivity, empathy, and shame: OUP Oxford.

Zajdow, G., \& MacLean, S. (2014). "I Just Drink for That Tipsy Stage”: Young Adults and Embodied Management of Alcohol Use. Contemporary Drug Problems, 41(4), 522-535. 
TABLES

Table 1: Establishment and Consistency of a Threshold of Too Much Alcohol

\begin{tabular}{|c|c|}
\hline Participant & Establishing a Level of Too Much \\
\hline $\begin{array}{l}\text { Female (20yrs) } \\
\text { P7 }\end{array}$ & $\begin{array}{l}\text { Over time I have learnt that when I } \\
\text { drink too much alcohol I end up feeling } \\
\text { incredibly sick and the room is } \\
\text { spinning, so now I aim to avoid this } \\
\text { point. I can sense when I'm starting to } \\
\text { feel that way so I stop drinking and } \\
\text { have some water. This has changed over } \\
\text { time as when I first started drinking I } \\
\text { had no idea what was too much and } \\
\text { would just continue drinking. }\end{array}$ \\
\hline $\begin{array}{l}\text { Male (21yrs) } \\
\text { P105 }\end{array}$ & $\begin{array}{l}\text { I have a good personal gauge of certain } \\
\text { drinks that make me more drunk than } \\
\text { other drinks. I can also tell when I am } \\
\text { near to my limit of drinks and will act } \\
\text { accordingly. This is not based on } \\
\text { counting drinks or specific } \\
\text { measurements as the amount depends } \\
\text { on a variety of things including if you } \\
\text { have eaten, how hydrated you are, } \\
\text { illness etc. }\end{array}$ \\
\hline
\end{tabular}

Is That Level Consistent or Changeable?

Female (23yrs) I'm not $100 \%$ sure that I would always P111 know what too much is. I am very aware when I am drinking to NOT drink too much but there have been occasions when I have had a little too much and only realised retrospectively. My sense of too much has definitely changed over time. When I was much younger I would go out, have pre-drinks and aim to get as drunk as possible and I would never do that now.

Male (19yrs)

P112

I established this sense through previous drinking experiences. It is extremely rare that I drink so much that I vomit, but after having done so a It usually remains consistent. However, sometimes I feel as though I am reaching that point quicker if I have not eaten much before drinking or if I haven't had a night out drinking for a while.

Fluctuates according to the situation. For example if I was drinking with my family or at a dinner party my limit would be considerably lower than my limit for going out clubbing.

It definitely depends on who I'm with. If I'm having a meal at a friend's house with alcohol or at home then I don't mind so much how much I'm drinking because I'm where I'm safe. If I'm out with people I don't know so well or on a work night out for example, I will drink less or not at all. couple of times I now know when I have had too much and that it is time to stop drinking. If I don't, I know I'll run the risk of being sick. This sense has improved over time.

It fluctuates. Say, for example, I was having a casual drink in the pub with my parents, I'd limit myself to a couple of drinks, not because I think I'm going to be sick, but merely because I don't like getting "drunk" around them. However, if I was out with friends at a club, then I'd be able to drink more without thinking that I've had too much. 
Table 2: Approaching and then Exceeding the Threshold of Too Much Alcohol

\begin{tabular}{|c|c|c|c|}
\hline Group & Participant & Approaching Too Much & Exceeding Too Much \\
\hline \multirow[t]{2}{*}{$\begin{array}{l}\text { Group 1: } \\
\text { Entirely } \\
\text { negative } \\
\text { embodied } \\
\text { approach }\end{array}$} & $\begin{array}{l}\text { Male (21yrs) } \\
\text { P2 }\end{array}$ & $\begin{array}{l}\text { I realize I cannot communicate } \\
\text { properly. In my head I know } \\
\text { what I need to say but the } \\
\text { words won't come out. I get } \\
\text { overly compulsive of checking I } \\
\text { have my phone, keys and } \\
\text { wallet. I will have a fear of } \\
\text { being sick and the } \\
\text { embarrassment of being caught } \\
\text { by friends or kicked out of a } \\
\text { club/bar. Vision is impaired } \\
\text { and I get a headache trying to } \\
\text { focus on something. }\end{array}$ & $\begin{array}{l}\text { All sense of well-being goes } \\
\text { out of the window. I know I am } \\
\text { drunk but do not care of the } \\
\text { consequences. Rely } 100 \% \text { on } \\
\text { other people to get home. } \\
\text { Majority of the time I will be } \\
\text { sick and make a mess of } \\
\text { myself. The next morning is } \\
\text { my own personal hell and the } \\
\text { hangovers can last up to } 2 \\
\text { days. }\end{array}$ \\
\hline & $\begin{array}{l}\text { Female (20yrs) } \\
\text { P62 }\end{array}$ & $\begin{array}{l}\text { I would feel very drunk, sick } \\
\text { and dizzy. My thoughts are "I } \\
\text { really need to stop drinking } \\
\text { now". However, I usually have } \\
\text { trouble following my own } \\
\text { thoughts and feelings and tend } \\
\text { to think it's a good idea to carry } \\
\text { on. }\end{array}$ & $\begin{array}{l}\text { I personally cannot describe } \\
\text { this as it is usually when I } \\
\text { blank out and do not } \\
\text { remember what is going on. }\end{array}$ \\
\hline
\end{tabular}

Group 2: $\quad$ Male (20yrs) P73

Entirely

positive

embodied

approach
The feeling of being happy, not caring about anything, just having fun with my friends. However I am acutely aware I shouldn't be drinking any more as I don't want to become out of control, so I drink water or soft drinks so I don't exceed myself.

Female (21yrs) I am happy/bubbly and P72 enjoying my evening with friends. My self-esteem increases and I feel more free from judgement.
I feel tired, anxious, start to feel ill and have double vision.
When I exceed too much, I lose control of my actions. I am never violent but I do not have the self-control to hold back from things. Everything in my head is a blur and any more alcohol and I do not remember anything. 